\title{
The Role of Teachers in the Organization of Inclusive Education of Primary School Pupils
}

\author{
Yuliia M. Shevchenko ${ }^{1}$, Svitlana M. Dubiaha ${ }^{1}$, Valentyna D. Melash ${ }^{1}$, Tetyana V. Fefilova ${ }^{1} \&$ Yulia O. Saenko ${ }^{1}$ \\ ${ }^{1}$ Department of Elementary Education, Educational and Scientific Institute of Social-Pedagogical and Artistic \\ Education, Bogdan Khmelnitsky Melitopol State Pedagogical University, Melitopol, Ukraine \\ Correspondence: Yuliia M. Shevchenko, Bogdan Khmelnitsky Melitopol State Pedagogical University, 20 Lenina str., \\ Melitopol, 72312, Ukraine.
}

Received: June 10, 2020

Accepted: August 3, 2020

Online Published: August 7, 2020

doi:10.5430/ijhe.v9n7p207

URL: https://doi.org/10.5430/ijhe.v9n7p207

\begin{abstract}
The article highlights the models of inclusive education of Italy, Germany, Sweden, Norway, and Great Britain. Inclusion models can be classified into three basic ones, according to the ratio of the number of primary school-aged children at general and specialized schools, namely: full inclusion, partial inclusion with a predominance of pupils at general schools, partial inclusion with a predominance of pupils at specialized schools. Full inclusion is present in Italy and Norway, partial inclusion with a predominance of students at specialized schools is observed in Sweden $(88.40 \%)$, partial inclusion with a predominance of students at general schools is present in Germany and the UK.

Models of inclusion differ on the following aspects: legal regulation, funding and amounts of financing for teachers' trainings, initial and ongoing teachers' training, an approach to the organization of inclusive education (partnership, peer-to-peer approach, centralized, decentralized), the practice of exchanging experiences of inclusion's organization within the country, the ratio of the number of primary school-aged children at general and specialized schools. The factors specified determine the role of teachers in the organization of inclusive education of primary school pupils. In countries, support and assistance of teachers is provided at different institutional levels: in Germany - through the center for psychological and pedagogical support, inclusion support services; in Great Britain - by assistants; in Italy - by consultants, healthcare service professionals; in Sweden - through resource centers; in Norway - through state centers. Support of teachers' professional development throughout life and teachers' financial motivation have been introduced in the countries; thus, these measures have a positive effect on the integration of primary school pupils in the society.
\end{abstract}

Keywords: inclusive education, primary school pupils, primary education, perception of inclusion by teachers

\section{Introduction}

Teachers are key figures in the process of ensuring the effective organization of inclusive education for primary school pupils. Taking into consideration the introduction of lifelong learning, changes in approaches to financing of inclusion (from centralized to decentralized), systematic updating of legislation, development of teachers' training and skills enhancement program in the field of inclusive education, the necessity arises to study the main trends and features of inclusion models in EU countries.

The need for models' transformation arises due to a number of external and internal factors. During the period 2014-2018, the reform of inclusive education and the transformation of the role of teachers in the organization of inclusive education have become a problem in many EU countries (Nxumalo, 2018). An integrated approach to implementing school inclusion reform remains basic nowadays.

Recent investigations confirm the importance in the organization of inclusive education in relation to the inclusion process, the perception of teaching methods and resources by various subjects of inclusion (Paseka \& Schwab, 2020). Among the factors of the effectiveness of inclusion models, the role of teachers is a special factor that is formed under the influence of the adopted legislative changes, the practice of inclusion and the exchange of experience in the organization of inclusive education. Competences of educators, formed through training and skills enhancement programs, ensure the effectiveness of adaptation and integration of primary school pupils into the society. "The greatest influence on the educational and social outcomes of pupils with special educational needs is the behavior and practices of the classroom teacher" (Efthymiou \& Kington, 2017). The purpose of the academic paper was to 
study and generalize the role of teachers in the organization of inclusive education of primary school children based on the analysis of the experience of inclusion in Italy, Germany, Sweden, Norway, and the United Kingdom.

The basic objectives of the study are defined as follows:

1. Studying and generalization of research results on the organization of inclusion of primary school children in Italy, Germany, Sweden, Norway, and the United Kingdom.

2. Analysis of tasks, functions of teachers in the organization of inclusion of junior schoolchildren in Italy, Germany, Sweden, Norway, and the United Kingdom.

3. Comparison of experience in the organization of inclusion and the role of teachers in different EU countries.

\section{Literature Review}

The role of teachers in the organization of inclusive education of primary school pupils has been proven in a number of scientific experimental studies. An analysis of the scientific literature, starting from 2000 to 2020, confirms the importance of the following key factors that determine the organization of inclusive education and depend on teachers, namely: 1) persuasion, positive attitude, constructionist approach and perception of inclusion by teachers, which can be formed through training, completion of qualification programs, while gaining inclusion experience (Avissar, Reiter \& Leyser, 2003; Avramidis \& Norwich, 2002; Corbett, 1999; Zambelli \& Bonni, 2004); 2) "communication competences of teachers" (Lancaster, 2014); 3) the ability to use a partnership approach (Lancaster, 2014); 4) self-efficacy of teachers (Kiel, Braun, Muckenthaler, Heimlich \& Weiss, 2019); 5) competence of educators (Tangen, 2005).

"The teachers experienced having a central role in providing continuous support to pupils with different learning disabilities within the support system" (Eklund, Sundqvist, Lindell \& Toppinen, 2020). In addition to the importance of teachers in the organization of inclusive education, the significance of specialists who provide support to teachers should be emphasized. "The support from colleagues (i.e. special education teachers) was seen as very important, although their experience of consultation time was limited" (Eklund et al., 2020). "Teachers' positive attitude to inclusion corresponds to more active implementation of inclusion curricula" (Avramidis \& Kalyva, 2007). "The prerequisite for positive persuasion of teachers is long-term teachers' training" (Arthur-Kelly, Sutherland, Lyons, Macfarlane \& Foreman, 2013) and "evaluation of their attitude to inclusion before its implementation" (Tangen, 2005). "The dominant belief about the teacher's role in teaching pupils with developmental difficulties appeared to be self-centered orientation" (Domović, Vlast \& Bouillet, 2017). Teachers' self-efficacy ensures the effectiveness of inclusion. As a result of the synergy of these factors, the process of organizing inclusion will be effective and provide the following social effects: 1) provision a deserved position of primary school pupils in the society, as well as their adaptation in the social medium; 2) establishing interpersonal relationships between pupils and teachers; 3) positive attitude to the integration of pupils with special educational needs in the society.

The identified factors and effects of inclusion depend on the process of organizing the education of primary school pupils. In EU countries, the organization of inclusion is "entrusted to a responsible person, whose role depends on funding, operational responsibilities, mental and physical support" (Cole, 2005). Teachers' personal competences determine their "ability to organize inclusion and provide a positive impact on the level of satisfaction of primary school pupils, and therefore determine the effectiveness of inclusion" (Adderley et al., 2015).

\section{Data and Methodology}

The investigation is based on an integrated approach that combines elements of segregation, differentiation and integration in the education of primary school pupils in Europe (Nxumalo, 2018). The conceptual basis of the investigation was the study of (Göransson, Lindqvist, Klang \& Magnússon, 2018; Magnússon, 2015; 2020), where the methodology is based on studying recent publications on the features of the organization of inclusion and confirmation of the latest trends in statistics and legislation. Thus, the investigation is based on the following methods:

1) the secondary analysis of studies and publications for the period 2015-2020, where the role of teachers in the organization of inclusion is oulined, which allowed us to compare the disadvantages, advantages of inclusion models, and the organization of teachers' work as a key element of its effectiveness;

2) analysis of statistical data characterizing the inclusion models of Italy, Germany, Sweden, Norway, and the United Kingdom for the 2016/2017 academic years, which allowed to identify the prerequisites for the organization of teachers; 
3) analysis of legislative documents of Italy, Germany, Sweden, Norway, and the United Kingdom, which regulate the organization of teachers at the national and local level;

4) study and generalization of publications on the organization of teachers' work to confirm or refute the hypothesis of regional differences in the role of teachers in the organization of inclusive education.

The bibliometric analysis of scientific investigations on the subject of the teachers' role in inclusive teaching of pupils for the period from 2000 to 2020 was carried out in the article. Databases Research Gate, Crossruff and Science Direct have been used for the analysis. The search in the databases has been carried out according to the following criteria: the publication should contain empirical research results for the last 2015-2020; the results should assess the role of the teacher in the inclusion of primary pupils. Qualitative studies have been excluded in the analysis process.

To conduct an analysis, data from Italy, Germany, Sweden, Norway, and the United Kingdom have been used, due to the fact that these are the countries, where inclusion is actively implemented at all educational levels and experimental studies of the teachers' role in inclusive teaching of pupils are conducted. The data have been selected on the site European Agency for Special Needs and Inclusive Education for the period of the 2016/2017 academic year. Statistical and comparative analysis of inclusive education indicators in the countries has been used. Data have been analyzed for ISCED 1 (primary education) according to the International Standard Classification of Education. Primary education usually begins at the age 5,6 or 7, and has a typical duration of six years (OECD, Eurostat \& UNESCO Institute for Statistics, 2015).

\section{Results and Discussion}

The practice of EU countries concerning the organization of inclusive education of pupils is distinctly different, depending on social-demographic, political factors and cultural values. In Germany, the model of inclusive education is based on a system of special educational institutions, institutions of inclusive education, pedagogical centers for psychological and pedagogical support, inclusion support services funded by local governments. There is also the possibility for pupils to study at general schools, provided that there are specialized teachers at such schools.

The UK model is based on a public-private partnership that provides funding for teaching children with special educational needs. Inclusive education is carried out at private and state schools (with specially equipped classrooms). At the secondary school, children are provided with an assistant, who helps them communicate with the teacher and the children.

The model of full inclusion has been applied in Italy for more than thirty years; it is based on the organization of training at general educational institutions. Consultative specialists provide support to teachers. Healthcare service professionals provide advisory support based on children's diagnosis. Teachers' assistants work at schools; they are responsible for pupils' progress, and they help children in case of necessity.

Swedish practice indicates that inclusive education is organized at general educational institutions in the country, but special establishments occupy an important place in inclusive education. The inclusion model includes child rehabilitation centers, resource centers. However, according to recent studies in the country, there are "problems of increased segmentation of pupils at special educational institutions, and pupils are limited in their choice of school" (Magnússon, 2020).

The practice of inclusive education in Norway, where the education system has been reformed to ensure full inclusion of all educational institutions, indicates the effectiveness of inclusion organization. Pupils have a right of free choice of school. State centers provide assistance to certain pupils.

The countries differ significantly in the number of primary school pupils: the largest number of primary school pupils is observed in the UK, Germany and Italy. Sweden and Norway amount less number of primary school pupils. Almost $100,00 \%$ of primary school pupils study at the mainstream classes, however the indicator differs significantly in the UK and is $92,18 \%$, what can be seen from the Table 1.

The number of nine-year-olds also differs distinctly among the countries. The largest number of nine-year-olds is observed in Germany (729,8 thousand children), Great Britain - 677,0 thousand children, and Italy - 567,7 thousand children. The proportion of nine-year-olds, enrolled in education at all educational institutions in all countries, except the United Kingdom (91,86\%) approximates to $100,00 \%$, seen to the Table 2. 
Table 1. Population and enrollment of ISCED 1 level in the 2016/2017 academic year

\begin{tabular}{|c|c|c|c|c|c|}
\hline Indicator & Italy & Sweden & Germany & Norway & The UK \\
\hline 1.1 Actual population of children/pupils & 2825058 & 700662 & 2904278 & 447901 & 4121640 \\
\hline $\begin{array}{l}1.2 \text { Children/ pupils enrolled in all formal } \\
\text { educational settings }\end{array}$ & 2792414 & 701973 & 2954775 & 444638 & 3839280 \\
\hline $\begin{array}{l}\text { 1.4 Children/ pupils enrolled in mainstream formal } \\
\text { educational settings }\end{array}$ & 2790790 & 696448 & - & 443993 & 3799382 \\
\hline $\begin{array}{l}\text { 1.4 Children/ pupils enrolled in mainstream formal } \\
\text { educational settings (share from actual population) }\end{array}$ & $98,79 \%$ & $99,40 \%$ & - & $99,13 \%$ & $92,18 \%$ \\
\hline $\begin{array}{l}\text { 1.5 Children/ pupils enrolled in mainstream } \\
\text { groups/classes for at least } 80 \% \text { of the time }\end{array}$ & 2790790 & 696448 & 2868444 & 442592 & 3792916 \\
\hline $\begin{array}{l}1.5 \text { Children/ pupils enrolled in mainstream } \\
\text { groups/classes for at least } 80 \% \text { of the time (share } \\
\text { from actual population) }\end{array}$ & $98,79 \%$ & $99,40 \%$ & $98,77 \%$ & $98,81 \%$ & $92,02 \%$ \\
\hline
\end{tabular}

Source: European Agency for Special Needs and Inclusive Education (2020a, 2020b, 2020c, 2020d, 2020e)

Table 2. Age samples of nine-year-olds children/pupils enrolled in all formal educational settings in the 2016/2017 academic year

\begin{tabular}{|c|c|c|c|c|c|}
\hline Indicator & Italy & Sweden & Germany & Norway & The UK \\
\hline 2.1 Population aged & 567680 & 117707 & 729770 & 63409 & 677079 \\
\hline $\begin{array}{l}\text { 2.2. Children/ pupils enrolled in all formal educational } \\
\text { settings aged }\end{array}$ & 558757 & - & 728748 & 62830 & 621986 \\
\hline $\begin{array}{l}\text { 2.2. Children/ pupils enrolled in all formal educational } \\
\text { settings aged (share of population aged) }\end{array}$ & $98,43 \%$ & - & $99,86 \%$ & $99,09 \%$ & $91,86 \%$ \\
\hline $\begin{array}{l}\text { 2.4 Children/ pupils enrolled in mainstream formal } \\
\text { educational settings aged }\end{array}$ & 558516 & - & - & - & 614574 \\
\hline $\begin{array}{l}2.5 \text { Children/ pupils enrolled in mainstream } \\
\text { groups/classes for at least } 80 \% \text { of the time aged }\end{array}$ & 558516 & - & 702213 & - & 613344 \\
\hline
\end{tabular}

Source: European Agency for Special Needs and Inclusive Education (2020a, 2020b, 2020c, 2020d, 2020e)

In Sweden and the United Kingdom, the lowest proportion of pupils, enrolled in primary education, with an official decision of SEN in any form of education is observed: $0,89 \%$ and 2,31\%, respectively, seen to the Table 3 . In Italy the indicator is at the average level, while in Germany and Norway the indicator is high.

Countries also differ distinctly in the organization of primary school education: "in Italy and Norway, 98,66\% and $93,31 \%$ of primary school pupils, respectively, study in the mainstream settings (classes) of general secondary schools; in Sweden, only 11,60\% of primary school pupils study in the mainstream settings (classes) of general secondary schools; in Germany and the United Kingdom, half of the primary school pupils $(47,82 \%$ and $55,77 \%)$ study in the mainstream settings (classes) of general secondary schools". Thus, inclusion models vary fundamentally from country to country; this may be due to the severity of mental and physical disabilities and different special educational needs. Therefore, $1,34 \%$ and $2,11 \%$ of primary school pupils, respectively, attend separate special schools in Italy and Norway; in Sweden, $88,40 \%$ of primary school pupils attend separate special schools; in Germany and the United Kingdom, 52,18\% and 40,23\% of primary school pupils, respectively, attend separate special schools. The data specified stipulate differences in teachers' role concerning the organization of inclusive education of primary school pupils. Consequently, in Italy and Norway, "educators are more competent due to existence of national qualification and training programs, development of competences" (Tangen, 2005). 
Table 3. Children/pupils with an official decision of SEN in the 2016/2017 academic year

\begin{tabular}{lccccc}
\hline \multicolumn{1}{c}{ Indicator } & Italy & Sweden & Germany & Norway & UK \\
\hline $\begin{array}{l}\text { 3.1 Children/ pupils with an official decision of SEN in } \\
\text { any form of education }\end{array}$ & 90845 & 6250 & 165457 & 30582 & 95238 \\
$\begin{array}{l}\text { 3.1 Children/ pupils with an official decision of SEN in } \\
\text { any form of education (share from actual population of } \\
\text { children/learners, see Table 1) }\end{array}$ & $3.22 \%$ & $0.89 \%$ & $5.70 \%$ & $6.83 \%$ & $2.31 \%$ \\
$\begin{array}{l}\text { 3.2 Children/ pupils with an official decision of SEN } \\
\text { educated in mainstream groups/classes for at least 80\% } \\
\text { of the time }\end{array}$ & 89628 & 725 & 79126 & 28536 & 53114 \\
$\begin{array}{l}\text { 3.2 Children/ pupils with an official decision of SEN } \\
\text { educated in mainstream groups/classes for at least 80\% } \\
\text { of the time (share of any form of education) }\end{array}$ & $98,66 \%$ & $11,60 \%$ & $47,82 \%$ & $93,31 \%$ & $55,77 \%$ \\
$\begin{array}{l}\text { 3.4 Children/ pupils with an official decision of SEN } \\
\text { educated in separate special (pre)schools }\end{array}$ & 1217 & 5525 & 86331 & 645 & 38314 \\
$\begin{array}{l}\text { 3.4 Children/ pupils with an official decision of SEN } \\
\text { educated in separate special (pre)schools (share of any } \\
\text { form of education) }\end{array}$ & $1,34 \%$ & $88,40 \%$ & $52,18 \%$ & $2,11 \%$ & $40,23 \%$ \\
\hline
\end{tabular}

Source: European Agency for Special Needs and Inclusive Education (2020a, 2020b, 2020c, 2020d, 2020e)

Countries also differ in the development of the legal framework for the regulation of inclusive education and teachers' education and training. In Italy, the legal framework began to develop in 1971-1977, when inclusion at general and specialized schools was declared; in 1992, the basic law on the problems of pupils with disabilities was adopted (provided for the work of assistants, full integration of pupils); in 2000, the 'integrated system of interventions and social services' was definitively stated; in 2003 equal conditions for teachers' education and training were ensured. In 2015, the funding of training and education of teachers was legally identified in Italy (40 million euros allocated for professional training), 9,000 specialists on inclusion were engaged. Italy is the country with the highest expenditures on inclusion. In Italy, a partnership approach is applied: parents - school - community. Primary schools in Italy are based on Primary Education Science degree course with duration of 4 years (Scienze della formazione primaria). Pupils, with the help of teachers' support, have to choose specific courses in their curricula when drafting their learning agreement. Peer-to-peer approach is a basic approach to inclusion implementation. Teachers' assistance is carried out by special staff, as well as Territorial Support Centers (CTS) (network of schools). Educators should undergo an internship. Initial internship is $20 \%$ of training, support for specialization - $100 \%$. Special attention should be paid to risk identification courses for teachers, the purpose of which centers around assessment procedures and guidance, as well as didactic measures to be adopted by teachers in relation to both the pupil and the class group.

In Germany, the legal framework differs within the lands and districts, which define their own principles of inclusion according to educational and cultural characteristics with simultaneous responsibility of the entire federal state. Inclusion is regulated on the basis of such common legal documents, as: "Basic Law (Grundgesetz, Art. 3 - R1), Book Twelve of the Social Code (Sozialgesetzbuch XII - Sozialhilfe) and the Länder constitutions (R14-29), and special ones - legal documents of the lands and districts". This provides an exchange of practices and experiences in organization of inclusion. Teachers' life-long training has been taking place since 2004. Financing is carried out at the expense of the local budget (more than 90\%) with state assistance in some cases. Teachers' training is basically divided into two stages: a higher education course and practical pedagogical training. According to teachers' special needs, training takes 4.5 years at the university, with a further 1.5-2 years of practical training at school.

The first approaches to the organization of inclusion in Germany were formed in the 1970s during conducting experiments on the integration of children with disabilities at public schools. However, ratification of the UN Convention in Germany took place in 2009 (Klemm, 2015). Prior to ratification, some schools organized inclusive education on a voluntary basis; after ratification, the entire education system had to implement inclusion. The territories of Germany are endowed with sovereignty in the field of education, so there was an integration of the convention into federal law. This led to regional differences in the organization of inclusion: inclusion conditions, funding, access to school for students, choices of schools by parents. Therefore, the choice of school (specialized or 
public) is limited. Students are grouped into several classes for various organizational reasons (Paseka \& Schwab, 2020). Parents' rights are limited by the number of places at the school for inclusive education (Klemm, 2015). These aspects have influenced the statistics of inclusive education: In total, about 524000 SEN students study in Germany, which is $7,1 \%$ of all students. Over the last ten years, the inclusion rate has increased from $18,4 \%$ in 2008 to $39,3 \%$ in 2006 (the proportion of SEN students who have attended inclusive classes, compared to all SEN students) (Klemm, 2018). The differences in inclusion rates are observed between preschool, primary and secondary schools: there is a decrease from $67,0 \%$ (kindergarten) to 46,9\% (primary schools) and 29,9\% (secondary schools) (data for the 2013/14 academic school year), (Klemm, 2015). Compared to international statistics and other EU countries, the German model is considered moderately integrated: on average: 52,7\% (Statistics of the European Agency for Inclusive Education 2014). In Germany, there are regional differences and levels of inclusion: the figure differs from $82,8 \%$ in the city-state of Bremen and 26,3\% in Bavaria (Klemm, 2018).

Taking into consideration the inclusion of students with different needs at public schools, research shows that teachers use different teaching methods. The basic criteria are as follows: learning strategies; formulation of goals and criteria for achieving the success of inclusion; formation of stages of performance of tasks by students; adaptation of tasks according to available resources and needs of students; differentiation of teaching materials; constant monitoring of efficiency; feedback; exercises and repetition of material; interactive forms of learning; additional tasks and exercises (Werning \& Arndt, 2015). Inclusive learning methods require a more personalized approach to students from teachers, differentiation and cooperation (Lindner, Alnahdi, Wahl \& Schwab, 2019; Schwab, Sharma \& Hoffmann, 2019). Personalization involves teachers' perception of students as individuals and finding ways to communicate with students. The basic competences of teachers in this case are the ability to recognize the strengths of younger students with special educational needs and their support, interesting content, teaching methods, the ability to cope with the shortcomings of students. Differentiation involves the use of different teaching methods, the ability to apply them depending on the needs of the student. Indicators of the effectiveness of differentiation are the level of use of alternative methods in teaching by using interesting materials. Cooperation involves establishing good relations not only with students but also with staff, especially between class teachers and teachers with special needs and / or psychologists (Paseka \& Schwab, 2020).

Teachers should ensure the organization of inclusion of primary school students in three directions: inclusive culture; inclusive policy; inclusive practices. Inclusive culture involves the formation of trusting environment, the establishment of values of inclusion. Inclusive policy involves organizing support for diversity by proposing a variety of measures. Inclusive practices involve the organization of training and mobilization of resources to create a favorable place for study and recreation (providing technical equipment and an acceptable class space).

Recent studies show that the use of various inclusive methods, differentiation and personalization of methods contribute to a more positive attitude of teachers towards inclusive education (Sharma \& Sokal, 2016).

Resources of inclusive education are divided into personnel (teaching and non-teaching staff) and teaching and learning materials and special resources (Schneider, Klemm, Kemper \& Goldan, 2018). Accordingly, inclusive culture, inclusive policies and inclusive practices can be considered as resources in the framework of inclusive education. As a rule, the basic obstacle to successful inclusion's implementation is the lack of resources, including human resources, that meet the specific educational needs of students. The amount of resources and flexibility in use of available resources in Europe varies greatly. However, the success of inclusive education requires competent human resources. Germany allows schools to refuse a student's admission in case of absence of human resources (Klemm, 2015). The availability of resources and the level of provision of human resources determines the level of perception of inclusive education by teachers: a high level of positive attitude is connected with a high level of provision of personnel.

The inclusion system of Sweden is decentralized. The legal framework began to be updated since 2010; in 2020 The United Nations (UN) Convention on the Rights of the Child was adopted in the country. According to the legislation, local authorities should ensure the achievement of inclusion goals by teachers. Educators are responsible for operational functions. The organization of education of primary school pupils is legally enshrined in the Curriculum for the compulsory school, pre-school class and the recreation center, which defines the norms of behavior, values, knowledge and competences, responsibility of teachers and other conditions for organization of inclusion. $15 \%$ of the municipal budget is spent to finance inclusion. Resource centers provide support for Swedish teachers. In Sweden, there are three types of specialties for obtaining education of a primary school teacher, in particular, 1-3 years of studying for working with primary school pupils and passing training programs for working with children with special educational needs. 
In the international community, the Swedish inclusive education system is often considered as the most effective model. However, recently in Sweden there has been an increase in segregation of students in terms of performance and social-economic, immigration origin of students, groups with special educational needs (Magnússon, 2020). Recent studies have noted the dependence of the growth of the ability to choose a school and the reduction of inequality among different groups of students, increasing social segregation in the education system (Fjellman, 2019). At the same time, schools in Sweden are increasingly segregated by ethnic and social determinants (Bunar \& Ambrose, 2018).

Another problem of the Swedish inclusive education system is the limited choice of students with special needs compared to other students. Grouping and segregation of students takes place at specialized schools. The share of students with special educational needs is lower at other types of schools. As in other models of inclusive education in European countries, students with lower social-economic and migratory backgrounds have lower levels of school's choice (Cook \& Kiru, 2018). The third problem is the availability of financial resources for special educational support for private specialized schools (Magnússon, 2020).

According to official statistics, approximately $15 \%$ of primary school students with special educational needs in Sweden attend private schools (SNAE, 2018) with significant regional differences in this indicator (Magnússon, 2020). The level of students' achievement at private schools is higher than at municipal schools. This difference is explained in part by social-economic factors, social segregation (Hinnerich \& Jonas Vlachos, 2017).

The positive aspects of inclusion in Sweden are the emphasis on the student's need for special physical, social and organizational upbringing, not on his or her disabilities. Accordingly, the concept of students with special educational needs is more widely considered in Sweden than in other countries. The legislation only stipulates the provision of specialized education at a public school, if possible. If necessary, additional organizational restrictions are introduced: teaching of students with special educational needs in certain classes according to certain subjects. School principals are legally responsible for providing support to such students, documentation, and other organizational factors of inclusion. Since 2014, the differences between the concepts of "additional support" and "specialized suppor" have been distinguished in the country. Consequently, recent research indicates that $40 \%$ of students need specialized support and approximately $20 \%$ of students need additional support (Magnússon, 2020). Teachers, working with students with special needs (SNE), learn to work towards the development of inclusive school education; they are considered as an important resource of the school in order to provide additional support and prevent the need for special support. Teachers, as a rule, understand the special needs of students, pay attention to organization and teaching (Göransson et al., 2018).

The latest official statistics give evidence that approximately $1 \%$ of students receive education in certain groups at schools and the exponential growth of this share by age groups: approximately $3 \%$ of senior primary school students receive additional support (SNAE, 2018). Recent studies also reveal that difficulties in inclusion are connected with difficulties in teaching individual students with special educational needs, rather than organizational difficulties (Magnússon, 2015).

The legal framework of England in this area started being developed in 1996, having been improved in 2000. In 2014, the legislative base was updated defining organization of education for children with special educational problems. The legislation also contains legal regulations, governing the financing of inclusion of primary school pupils and discrimination. Financing is carried out on the basis of grants. According to the legislation, teachers must receive primary education and constantly improve their professional skills. The government has developed teaching materials for educators in accordance with the mental and physical disabilities of pupils. The Carter Review of Initial Teacher Training was adopted in England and it provided material motivation for teachers. Coordinators provide support to teachers in the basic areas of inclusion. The exchange of practice and experience in the sphere of inclusion is a characteristic feature of the development of teachers' competence.

The legislation of Norway separately regulates the acquisition of primary education by the Education Act, in particular, primary, lower-secondary and upper-secondary education. Curricula and subject curricula have been approved by specialized legislation. The legislation also regulates the requirements for teachers (motivation, competence and level of commitment) who seek to receive education in the field of inclusion. Funding of inclusion is decentralized, as well as general financing of schools also takes place. In Norway, priority is given to adaptive education and an individual approach to financing inclusion. Because of the decentralized approach, there is inequality in schools' funding. A partnership approach to inclusive education is being developed in the country. Teachers must undergo courses within the framework of national curricula. Since 2017, teachers have been studying under a five-year master's program. In addition, lifelong education and training have been introduced. 


\section{Conclusion}

The article has analyzed the models of inclusive education of Italy, Germany, Sweden, Norway and Great Britain. Inclusion models differ in the following aspects: legal regulation, funding and volumes of financing of teachers' education and training, initial and continuing teachers' training, approach to the organization of inclusive education (partnership, peer-to-peer approach, centralized, decentralized), practice of exchanging experience in the organization of inclusion within the country, the ratio of the number of primary-school-aged pupils at general and specialized schools. The factors specified determine the role of teachers in the organization of inclusive education of primary school pupils. In countries, support and assistance of teachers is provided at different institutional levels: in Germany - through the center for psychological and pedagogical support, inclusion support services; in Great Britain - by assistants; in Italy - by consultants, healthcare service professionals; in Sweden - through resource centers; in Norway - through state centers. Support of teachers' professional development throughout life and teachers' financial motivation have been introduced in the countries; thus, these measures have a positive effect on the integration of primary school pupils in the society.

The role of teachers in the organization of inclusive education of primary school students is a key one due to the high level of inclusion of primary school students (up to 50\%) at public schools. The level of their inclusion's perception in general depends on the ability and competences of teachers to ensure the personification and differentiation of inclusive teaching methods: a higher level of skills provides a more positive level of perception. An additional component of the teachers' role is participation in programs and strategies for the development of learning, which are characterized by regional differences. In general, in EU countries, inclusive education of primary school students does not cause difficulties connected with the organization, indicates a high level of competences of teachers. At the same time, the problems arise in the education of individual students who have special educational needs. In this case, personalization, differentiation and the proper form of education (public school or specialized school) determine the effectiveness of inclusion and the effectiveness of the teacher. An additional factor in the effectiveness of teachers and their perception of inclusion is the level of staffing, in particular the availability of teachers who have the necessary competences to work with certain educational needs of students.

\section{References}

Adderley, R. J., Hope, M. A., Hughes, G. C., Jones, L., Messiou, K., \& Shaw, P. A. (2015). Exploring inclusive practices in primary schools: focusing on children's voices. European Journal of Special Needs Education, 30(1), 106-121. https://doi.org/10.1080/08856257.2014.964580

Arthur-Kelly, M., Sutherland, D., Lyons, G., Macfarlane, S., \& Foreman, P. (2013). Reflections on enhancing pre-service teacher education programmes to support inclusion: Perspectives from New Zealand and Australia. European Journal of Special Needs Education, 28(2), 217-233. https://doi.org/10.1080/08856257.2013.778113

Avissar, G., Reiter, S., \& Leyser, Yo. (2003). Principals' views and practices regarding inclusion: the case of Israeli elementary school principals. European Journal of Special Needs Education, 18(3), 355-369. https://doi.org/10.1080/0885625032000120233

Avramidis, E., \& Norwich, B. (2002). Teachers' attitudes towards integration / inclusion: A review of the literature. European Journal of Special Needs Education, 17(2), 129-147. https://doi.org/10.1080/08856250210129056

Bunar, N., \& Ambrose, A. (2018). Urban polarization and market losses. In M. Dahlstedt \& A. Fejes (Eds.). School, market and future. Lund, Sweden: Studentlitteratur.

Cole, B. A. (2005). Mission impossible? Special educational needs, inclusion and the re-conceptualization of the role of the SENCO in England and Wales. European Journal of Special Needs Education, 20(3), 287-307. https://doi.org/10.1080/08856250500156020

Cook, N., \& Kiru, E. W. (2018). Disproportionality in special education: A synthesis of international research and trends. The Journal of Special Education, 52(3), 163-173. https://doi.org/10.1177/0022466918772300

Corbett, J. (1999). Inclusive education and school culture. International Journal of Inclusive Education, 3(1), 53-61. https://doi.org/10.1080/136031199285183

Domović, V., Vlast, V. V., \& Bouillet, D. (2017). Student teachers' beliefs about the teacher's role in inclusive education. European Journal of Special Needs Education, 32(2), 175-190. https://doi.org/10.1080/08856257.2016.1194571

Efthymiou, E., \& Kington, A. (2017). The development of inclusive learning relationships in mainstream settings: A multimodal perspective. Cogent Education, 4(1), 1304015 https://doi.org/10.1080/2331186X.2017.1304015 
Eklund, G., Sundqvist, Ch., Lindell, M., \& Toppinen, H. (2020). A study of Finnish primary school teachers' experiences of their role and competences by implementing the three-tiered support. European Journal of Special Needs Education, 28(41). https://doi.org/10.1080/08856257.2020.1790885

European Agency for Special Needs and Inclusive Education. (2020a). German data. Retrieved from https://www.european-agency.org/data/germany/datatable-overview\#tab-official_decision_on_sen

European Agency for Special Needs and Inclusive Education. (2020b). Italy data. Retrieved from https://www.european-agency.org/data/italy/datatable-overview\#tab-official_decision_on_sen

European Agency for Special Needs and Inclusive Education. (2020c). Norway data. Retrieved from https://www.european-agency.org/data/norway/datatable-overview\#tab-official_decision_on_sen

European Agency for Special Needs and Inclusive Education. (2020d). Sweden data. Retrieved from https://www.european-agency.org/data/sweden/datatable-overview\#tab-official_decision_on_sen

European Agency for Special Needs and Inclusive Education. (2020e). UK data. Retrieved from https://www.european-agency.org/data/uk-england/datatable-overview\#tab-population_and_enrolment

Fjellman, A. M. (2019). School choice, space and the geography of marketization - Analyses of educational restructuring in upper secondary education in Sweden. Gothenburg, Sweden: Gothenburg University.

Göransson, K., Lindqvist, G., Klang, K., Magnússon, G., \& Almqvist, L. (2018). Professionalism, governance and inclusive education - A total population study of Swedish special needs educators. International Journal of Inclusive Education, 170(243). https://doi.org/10.1080/13603116.2018.1441339

Hinnerich, B. T., \& Jonas Vlachos, J. (2017). The impact of upper-secondary voucher school attendance on student achievement. Swedish evidence using external and internal evaluations. Labour Economics, 47, 1-14. https://doi.org/10.1016/j.labeco.2017.03.009.

Kiel, E., Braun, A., Muckenthaler, M., Heimlich, U. \& Weiss, S. (2019). Self-efficacy of teachers in inclusive classes. How do teachers with different self-efficacy beliefs differ in implementing inclusion? European Journal of Special Needs Education, 28(41). https://doi.org/10.1080/08856257.2019.1683685

Klemm, K. (2015). Inclusion in Germany. Retrieved http://www.bertelsmann-stiftung.de/fileadmin/files/BSt/Publikationen/GrauePublikationen/Studie_IB_Klemm-S tudie_Inklusion_2015.pdf

Klemm, K. (2018). On the way to inclusive schools. Retrieved from http://www.bertelsmann-stiftung.de/fileadmin/files/BSt/Publikationen/GrauePublikationen/Studie_IB_Unterweg s-zur-inklusiven-Schule_2018.pdf

Lancaster, J. (2014). School and classroom indicators of inclusive education. Measuring Inclusive Education International Perspectives on Inclusive Education, https://doi.org/10.1108/S1479-363620140000003027

Lindner, K. T., Alnahdi, G. H., Wahl, S., \& Schwab, S. (2019). Perceived differentiation and personalization teaching approaches in inclusive classrooms: Perspectives of students and teachers. Frontiers in Education, 4(58). https://doi.org/10.3389/feduc.2019.00058

Magnússon, G. (2015). Traditions and challenges. Special support in Swedish independent compulsory schools. Doctoral dissertation. Retrieved from http://urn.kb.se/resolve?urn=urn:nbn:se:mdh:diva-28823

Magnússon, G. (2020). Inclusive education and school choice lessons from Sweden. European Journal of Special Needs Education, 35(1), 25-39. https://doi.org/10.1080/08856257.2019.1603601

Nxumalo, C. (2018). Inclusive school reform in Swaziland. Oxford: Oxford Research Encyclopedia of Education. https://doi.org/10.1093/acrefore/9780190264093.013.436

OECD, Eurostat \& UNESCO Institute for Statistics. (2015). ISCED 2011 operational manual: Guidelines for classifying national education programmes and related qualifications. Retrieved from http://doi.org/10.1787/9789264228368-en

Paseka, A., \& Schwab, S. (2020). Parents' attitudes towards inclusive education and their perceptions of inclusive teaching practices and resources. European Journal of Special Needs Education, 35(2), 254-272. https://doi.org/10.1080/08856257.2019.1665232

Schneider, K., Klemm, K., Kemper, T., \& Goldan, J. (2018). The third report on the evaluation of the law on the 
promotion of municipal expenditure on the inclusion of schools in North Rhine-Westphalia. Retrieved from http://www.wib.uni-wuppertal.de/forschung/projekte/evaluation-kommunaler-aufwendungen-fuer-die-schulisch e-inklusion.html

Sharma, U., \& Sokal, L. (2016). Can teachers' self-reported efficacy, concerns, and attitudes toward inclusion scores predict their actual inclusive classroom practices? Australasian Journal of Special Education, 40(1), 21-38. https://doi.org/10.1017/jse.2015.14

SNAE. (2018). Special support in the primary school. Stockholm, Sweden: Skolverket.

Tangen, R. (2005). Promoting inclusive education in secondary school in Norway: A national curriculum for teacher development. European Journal of Special Needs Education, 20(1), 57-70. https://doi.org/10.1080/0885625042000319089

Werning, R., \& Arndt, A.-K. (2015). Teaching and inclusion. In E. Kiel (Ed.). Inclusion in secondary schools. Stuttgart, Germany: Kohlhammer.

Zambelli, F., \& Bonni, R. (2004). Beliefs of teachers in Italian schools concerning the inclusion of disabled students: A q-sort analysis. European Journal of Special Needs Education, 19(3), 351-366. https://doi.org/10.1080/0885625042000262505 